\title{
Fat oxidation at rest and during exercise in male monozygotic twins
}

\author{
Jari E. Karppinen ${ }^{1,2}\left(\mathbb{C}^{\circ} \cdot\right.$ Mirva Rottensteiner $^{1,3}\left(\mathbb{D} \cdot\right.$ Petri Wiklund $^{1,4,5} \cdot$ Kaisa Hämäläinen $^{6} \cdot$ Eija K. Laakkonen $^{1,2}(\mathbb{D} \cdot$ \\ Jaakko Kaprio $^{7,8}$ ([) $\cdot$ Heikki Kainulainen ${ }^{1}$ (1) . Urho M. Kujala $\left.{ }^{1}\right]$
}

Received: 29 January 2019 / Accepted: 24 October 2019 / Published online: 31 October 2019

(c) The Author(s) 2019

\begin{abstract}
Purpose We aimed to investigate if hereditary factors, leisure-time physical activity (LTPA) and metabolic health interact with resting fat oxidation (RFO) and peak fat oxidation (PFO) during ergometer cycling.

Methods We recruited 23 male monozygotic twin pairs (aged 32-37 years) and determined their RFO and PFO with indirect calorimetry for 21 and 19 twin pairs and for 43 and 41 twin individuals, respectively. Using physical activity interviews and the Baecke questionnaire, we identified 10 twin pairs as LTPA discordant for the past 3 years. Of the twin pairs, 8 pairs participated in both RFO and PFO measurements, and 2 pairs participated in either of the measurements. We quantified the participants' metabolic health with a 2-h oral glucose tolerance test.

Results Fat oxidation within co-twins was correlated at rest [intraclass correlation coefficient (ICC) $=0.54,95 \%$ confidence interval (CI) 0.15-0.78] and during exercise (ICC $=0.67,95 \%$ CI 0.33-0.86). The LTPA-discordant pairs had no pairwise differences in RFO or PFO. In the twin individual-based analysis, PFO was positively correlated with the past 12-month LTPA $(r=0.26, p=0.034)$ and the Baecke score $(r=0.40, p=0.022)$ and negatively correlated with the area under the curve of insulin $(r=-0.42, p=0.015)$ and glucose $(r=-0.31, p=0.050)$ during the oral glucose tolerance test.

Conclusions Hereditary factors were more important than LTPA for determining fat oxidation at rest and during exercise. Additionally, PFO, but not RFO, was associated with better metabolic health.
\end{abstract}

Keywords Twins · Exercise $\cdot$ Lipid metabolism $\cdot$ Oral glucose tolerance

Communicated by Philip D Chilibeck.

Jari E. Karppinen

jari.e.j.karppinen@jyu.fi

1 Faculty of Sport and Health Sciences, University of Jyväskylä, Jyväskylä, Finland

2 Gerontology Research Center, Faculty of Sport and Health Sciences, University of Jyväskylä, Jyväskylä, Finland

3 Department of Medicine, Central Finland Health Care District, Jyväskylä, Finland

4 Exercise Translational Medicine Center and Shanghai Center for Systems Biomedicine, Shanghai Jiao Tong University, Shanghai, China

5 Department of Epidemiology and Biostatistics, Centre for Environment and Health, School of Public Health, Imperial College London, London, UK

$6 \quad$ FirstBeat Technologies Ltd, Jyväskylä, Finland

7 Department of Public Health, University of Helsinki, Helsinki, Finland

8 Institute for Molecular Medicine Finland, University of Helsinki, Helsinki, Finland

\section{Abbreviations}

AUC Area under the curve

DXA Dual-energy x-ray absorptiometry

ICC Intraclass correlation coefficient

LBM Lean body mass

LTPA Leisure-time physical activity

MET Metabolic equivalent of task

MZ Monozygotic

OGTT Oral glucose tolerance test

PFO Peak fat oxidation

REE Resting energy expenditure

RER Respiratory exchange ratio

RFO Resting fat oxidation

$\mathrm{VCO}_{2} \quad$ Volume of carbon dioxide

$\mathrm{VO}_{2} \quad$ Volume of oxygen

$\mathrm{VO}_{2 \text { peak }}$ Peak oxygen uptake 


\section{Introduction}

Fat oxidation rates at rest (Goedecke et al. 2000; Robinson et al. 2016) and during exercise (Venables et al. 2005; Randell et al. 2016; Fletcher et al. 2017) vary among individuals. The key determinants of resting fat oxidation (RFO) are not precisely identified in the scientific literature. During exercise, the main determinant of substrate use is exercise intensity (Romijn et al. 1993). The peak fat oxidation (PFO) rate is usually achieved at moderate exercise intensities ( 40-60\% of maximal oxygen uptake) (Venables et al. 2005; Randell et al. 2016; Fletcher et al. 2017), and the rate can be regarded as the highest systemic capacity to oxidise fat. The exercise intensity, where PFO is reached, is called FAT $_{\text {MAX }}$ (Achten et al. 2002). As reviewed by Maunder et al. (2018), the most important determinants of PFO are training status and testing modality, biological sex, as well as habitual and acute nutrition. Large cross-sectional studies have accounted for only $34-47 \%$ of the variance in PFO (Venables et al. 2005; Randell et al. 2016; Fletcher et al. 2017). Thus, a large part of the inter-individual variability in PFO remains unexplained. Genetic differences likely play an important role because several physical and performance traits, including maximal oxygen uptake (Bouchard et al. 1998), lean body mass (LBM), muscle strength (Arden and Spector 1997) and skeletal muscle fiber-type proportion (Simoneau and Bouchard 1995) have significant genetic components. Studies investigating the respiratory exchange ratio (RER) at rest and during exercise have demonstrated that the relative use of fatty acids in both conditions show familial resemblance (Bouchard et al. 1989; Toubro et al. 1998). However, to our knowledge, no researcher has studied the absolute fat oxidation rates at rest and during exercise among monozygotic (MZ) twins.

Previous observational studies (Venables et al. 2005; Randell et al. 2016; Fletcher et al. 2017) have highlighted the influence of modifiable lifestyle factors, such as physical activity, on the capacity to oxidise fats. As genes also affect physical activity participation (Stubbe et al. 2006; Mustelin et al. 2012; Aaltonen et al. 2013), observational studies possibly overestimate the influence of physical activity. Experimental studies can provide evidence on the cause-and-effect relationship; however, long-term exercise training trials investigating fat oxidation are rare because they are expensive and arduous to perform. An option to counteract the shortcomings and the difficulties of both study designs is to compare the fat oxidation capacity of MZ co-twins who are discordant in long-term physical activity. This study design controls for genetic predisposition and mostly for the impact of the childhood environment. Therefore, the possible difference between co-twins likely results from different physical activity habits.
Besides investigating the determinants of fat oxidation capacity, researchers have been interested in understanding whether fat oxidation capacity interacts with metabolic health. This seems plausible as efficient utilization of fatty acids could protect from e.g. insulin resistance (Phielix et al. 2012). Indeed, some studies have found an association between systemic fat oxidation and better metabolic health status (Hall et al. 2010; Rosenkilde et al. 2010; Robinson et al. 2015). However, obesity-related increase in fatty acid availability has also been linked to higher fat oxidation levels (Perseghin et al. 2002; Hodson et al. 2010; Ara et al. 2011; Dandanell et al. 2017a). Thus, it remains debated whether higher fat oxidation capacity is beneficial to metabolic health and more research is needed.

In this study, our goal was to investigate the influence of internal (genetics) and external (physical activity) factors on fat oxidation at rest and during exercise. Additionally, we aimed to examine the association between fat oxidation capacity and oral glucose tolerance test (OGTT)-induced metabolic response.

\section{Materials and methods}

\section{Participants and study design}

This study is part of the FITFATTWIN study, whose purpose was to identify possible pairwise differences in health and fitness parameters between male MZ co-twins (aged 32-37 years). The recruitment process was previously reported in detail (Rottensteiner et al. 2015). In short, the studied MZ twin pairs were identified from the longitudinal FinnTwin 16 cohort, which follows Finnish twins born from October 1974 to December 1979. The co-twins from 202 male MZ pairs provided data on their physical activities in an online survey, which formed the fifth wave of the FinnTwin 16 study data collection. This data was used to identify co-twins who were potentially discordant in leisuretime physical activity (LTPA). From the whole population, 39 twin pairs met the initial selection criteria and were selected to participate in a telephone interview, consisting of questions about their physical activities and health habits. Based on the interview, 20 twin pairs were invited to participate in the study; of these, 17 twin pairs accepted the invitation. Additionally, 6 twin pairs who were identified as concordant in LTPA were recruited from the FinnTwin16 cohort. These pairs were selected to represent varying physical activity levels, from sedentary to athletic. Thus, a total of 23 twin pairs participated in the laboratory measurements performed on 2 consecutive days. The complete timetable of the measurements was reported earlier as supplementary material in Rottensteiner et al. (2015). 
Of the 23 twin pairs, 19 pairs participated in the exercise test and 22 pairs participated in the resting metabolism measurement (18 pairs took part in both measurements). One twin individual's resting metabolism measurement was excluded due to hyperventilation. Thus, the analyses of genetic influence on PFO and RFO were conducted among 19 and 21 twin pairs, respectively. In total, PFO and RFO were determined for 41 and 43 twin individuals, respectively, and the twin individual-based analyses were conducted in these groups. One twin pair declined to participate in the OGTT, and the analyses between PFO or RFO and OGTT variables were performed in groups of 39 and 41 twin individuals, respectively.

Based on detailed LTPA interviews and a questionnaire (see the next subsection), 10 of the 23 twin pairs were identified as LTPA-discordant for the past 3 years. The determination of discordance was thoroughly explained by Rottensteiner et al. (2015). Of the 10 LTPA-discordant twin pairs, 8 pairs participated in both metabolism measurements, and 2 pairs took part in one of the measurements. Therefore, a pairwise comparison on the effect of LTPA on PFO or RFO was performed between 9 twin pairs, respectively.

\section{Leisure-time physical activity (LTPA)}

The LTPA level was determined with two separate interviews and the Baecke questionnaire. A brief retrospective interview (Waller et al. 2008; Leskinen et al. 2009; Rottensteiner et al. 2015), including structured questions on the LTPA's average frequency, duration, and intensity, as well as the average frequency and duration of commuting, was used to estimate the total LTPA volume at 1-year intervals over the past 6 years. The LTPA volume was calculated by multiplying the activity's monthly frequency, minute duration and metabolic equivalent of task (MET)-intensity and commuting physical activity was calculated by multiplying the standard 4-MET intensity with the daily commuting minute duration and the weekly frequency (5 times a week). The total LTPA volume was expressed as the sum score of the daily MET-hours, and the mean LTPA (MET-h/day) over the past 3 years (3-year LTMET index) was used to describe each participant's activity level.

A more thorough interview was used to estimate the past 12-month LTMET index. The interview was based on the Kuopio Ischemic Heart Disease Risk Factor Study Questionnaire (Lakka and Salonen 1997), with additional physical activities. The participants were asked about the number of times per month (and the average duration) they participated in 20 different types of physical activities or other physical activities specified by each respondent. The participants were also asked to classify the intensity of each activity based on a 4-level scale. Like the past 3-year LTMET index, the 12-month LTMET index was calculated as MET-h/day.
The participants also completed a 16-item Baecke questionnaire, which measured their recent work, sports and LTPA (Baecke et al. 1982). The total sum score was used for the twin individual-based analysis.

\section{Peak oxygen uptake $\left(\mathrm{VO}_{2 \text { peak }}\right)$ and peak fat oxidation (PFO)}

A graded incremental exercise test with a gas-exchange analysis was performed on the first day of the laboratory visit. The participants were instructed to avoid vigorous exercise and alcohol use $48 \mathrm{~h}$ and avoid eating $2 \mathrm{~h}$ prior to testing. The exercise test was performed with an electrically braked bicycle ergometer (Ergoselect 200, Ergoline $\mathrm{GmbH}$, Germany). The testing began with a 2-min stage at $20 \mathrm{~W}$, followed by a 2-min stage at $25 \mathrm{~W}$. Next, the work rate increased by $25 \mathrm{~W}$ every 2 min until volitional exhaustion. The breath-by-breath gas exchange was recorded with a Vmax Encore 29 metabolic cart (Sensormedics, Yorba Linda, CA, USA), which was calibrated according to the manufacturer's instructions before each measurement. The volume of oxygen $\left(\mathrm{VO}_{2}\right)$ inspired and the volume of carbon dioxide $\left(\mathrm{VCO}_{2}\right)$ expired were averaged at 30-s intervals for the whole test duration. The $\mathrm{VO}_{2 \text { peak }}$ was determined as the average of the two highest consecutive $\mathrm{VO}_{2}$-measurements Fat oxidation was calculated for each exercise stage from the last 30-s period with Frayn's (1983) equation, assuming that the urinary nitrogen excretion was negligible. The highest calculated fat oxidation rate was selected as the PFO and the corresponding exercise intensity as the $\mathrm{FAT}_{\mathrm{MAX}}\left(\% \mathrm{VO}_{2 \text { peak }}\right)$. Each participant's heart rate and cardiac function were monitored continuously with a 12-lead electrocardiography system (CardioSoft v.5.02 GE Medical System Corina, GE Medical System Inc., USA). The rating of perceived exertion (RPE) was determined at the end of each stage with the Borg (6-20) scale (Borg 1982). The exercise test was classified as maximal if the RPE was 19-20/20 or the RER was $>1.1$ at the end of the test. The exercise test protocol was submaximal for 4 subjects. Among the participants tested with the submaximal protocol, their fat oxidation rates declined before their last performed exercise stage. Thus, their PFO results were included in the study, and their $\mathrm{VO}_{2 \text { peak }}$ was extrapolated based on the submaximal results.

\section{Body composition}

Each participant's body composition was measured in the morning of the second measurement day, following overnight fasting. For the body mass and height measurements, the participants were barefoot and wore light outfits. Their body mass and height were respectively measured using an electronic scale with a $0.1-\mathrm{kg}$ accuracy and a stadiometer with a $0.5-\mathrm{cm}$ accuracy. Their total mass, LBM, fat mass and 
body fat percentage were measured with dual-energy x-ray absorptiometry (DXA) (DXA Prodigy, GE Lunar Corp., Madison, WI, USA).

\section{Resting metabolism}

Each participant's resting metabolism was measured (after the DXA measurement) in a dimly light room. Similar to the exercise test, the same Vmax Encore 29 metabolic cart was used and calibrated accordingly. First, the participants rested $10 \mathrm{~min}$ in a supine position. Then, their gas exchange was recorded for $16 \mathrm{~min}$ using the ventilated canopy method, and their $\mathrm{VO}_{2}$ and $\mathrm{VCO}_{2}$ were averaged at 1-min intervals. First 5 min measurement data were excluded. Resting metabolism variables were calculated from a steady-state measurement period $\left(\mathrm{VO}_{2}\right.$ and $\mathrm{VCO}_{2}$ coefficient of variation $\leq 10 \%$ between minutes). The average steady-state duration was $9.2 \pm 2.7 \mathrm{~min}$. The resting energy expenditure (REE) was calculated with the modified Weir equation (Weir 1949; Mansell and Macdonald 1990), and Frayn's (1983) equation was used to calculate the RFO. A protein correction factor of $0.11 \mathrm{mg} / \mathrm{kg} / \mathrm{min}$ was applied to take into account the nitrogen exertion (Flatt et al. 1985; Hall et al. 2010; Robinson et al. 2016).

\section{Metabolic health}

A standard 2-h OGTT followed the resting metabolism measurement. After the collection of their fasted blood samples, the participants ingested a 75-g glucose solution (GlucosePro, Comed LLC, Tampere, Finland). Next, their blood samples were collected at 30-min, 1-h and 2-h intervals post-ingestion. All blood samples were collected from each participant's antecubital vein when he was in a supine position. The plasma glucose concentration was analysed with Konelab 20 XT (Thermo Fisher Scientific, Vantaa, Finland) and the serum insulin concentration was analysed using IMMULITE® 1000 (Siemens Medical Solution Diagnostics, Los Angeles, CA, USA). The Matsuda index was determined based on the equation: 10,000/square root of [(fasting glucose $\times$ fasting insulin) $\times$ (mean glucose $\times$ mean insulin during OGTT)] (Matsuda and DeFrozo 1991). Additionally, the area under the curve (AUC) was calculated for insulin and glucose with the trapezoidal method.

\section{Ethical approval}

Good clinical and scientific practices and guidelines, as well as the Declaration of Helsinki, were followed while conducting the study. The study was approved by the Ethics Committee of the Central Finland Health Care District (Dnro
4U/2011). All participants provided their written informed consent before the laboratory measurements.

\section{Statistical analysis}

Statistical analysis was carried out with IBM SPSS Statistics 24.0 and Stata 15.0. A one-way random model was used to calculate the intraclass correlation coefficients (ICCs) between the MZ co-twins. An ICC compares within-pair variation with between-pair variation and thus explains how similar the co-twins are when compared with the other pairs. Pairwise correlations and differences were analysed with Pearson correlation coefficient and paired-sample $t$ test, respectively. Twin individual-based correlations were analysed with simple linear regression, and the within-pair dependency was taken into account (Williams 2000) with the clustering option of Stata. In all regression analyses, RFO or PFO was treated as the dependent variable. All the variables or the regression analysis residuals were determined normally distributed with the Shapiro-Wilk test or with the visual inspection of the histograms and the normality plots. The $p$ value 0.05 was selected to represent statistical significance. For clarity, RFO or PFO without a unit symbol is used in the text when the statistical significance persists both when using absolute or LBM relative values in the analysis.

\section{Results}

\section{Participant characteristics}

Table 1 presents the participant characteristics. Overall, the study population consisted of healthy men (aged 32-37 years) with varying physical activity, body composition and cardiorespiratory fitness levels.

\section{Hereditary factors and metabolism at rest and during exercise}

The calculated ICCs of the resting metabolism variables and PFO showed significant resemblance between co-twins (Table 2). We also categorised the co-twins as more active or less active based on their 12-month LTMET index to calculate pairwise correlations (Figs. 1 and 2). This division did not lead to significant mean differences between the groups in RFO $(0.001 \mathrm{~g} / \mathrm{min}, p=0.68)$ or PFO $(0.02 \mathrm{~g} /$ $\min , p=0.47$ ).

\section{LTPA and metabolism at rest and during exercise}

Table 3 presents the results of the pairwise comparison between the LTPA-discordant co-twins $(n=9-10)$. Figure 3 illustrates individual RFO and PFO results and 
Table 1 Characteristics of the participants $(n=46)$

\begin{tabular}{|c|c|c|c|}
\hline & Mean \pm SD & Minimum & Maximum \\
\hline Age & $34.5 \pm 1.5$ & 32 & 37 \\
\hline \multicolumn{4}{|l|}{ Body composition } \\
\hline Height $(\mathrm{cm})$ & $178 \pm 7$ & 157 & 190 \\
\hline Body mass (kg) & $76.7 \pm 9.8$ & 51.5 & 96.2 \\
\hline BMI $\left(\mathrm{kg} / \mathrm{m}^{2}\right)$ & $24.1 \pm 2.7$ & 19.8 & 33.6 \\
\hline Lean body mass (kg) & $56.8 \pm 7.0$ & 40.4 & 73.2 \\
\hline Fat mass $(\mathrm{kg})$ & $16.7 \pm 6.7$ & 5.2 & 31.6 \\
\hline Body fat percentage (\%) & $21.4 \pm 6.7$ & 7.6 & 36.0 \\
\hline \multicolumn{4}{|l|}{ Physical activity } \\
\hline 3-year-LTMET index (MET-h/day) & $4.7 \pm 4.6$ & 0.2 & 18.3 \\
\hline 12-month-LTMET index (MET-h/day) & $4.2 \pm 4.6$ & 0.1 & 27.7 \\
\hline Baecke questionnaire (score) & $8.3 \pm 1.3$ & 5.6 & 12.1 \\
\hline \multicolumn{4}{|l|}{ Cardiorespiratory fitness ${ }^{\mathrm{a}}$} \\
\hline $\mathrm{VO}_{2 \text { peak }}(1 / \mathrm{min})$ & $3.2 \pm 0.6$ & 2.3 & 4.6 \\
\hline $\mathrm{VO}_{2 \text { peak }}(\mathrm{ml} / \mathrm{kg} / \mathrm{min})$ & $41 \pm 9$ & 29 & 66 \\
\hline $\mathrm{VO}_{2 \text { peak }}(\mathrm{ml} / \mathrm{kg} \mathrm{LBM} / \mathrm{min})$ & $55 \pm 8$ & 40 & 75 \\
\hline \multicolumn{4}{|l|}{ Resting metabolism ${ }^{\mathrm{b}}$} \\
\hline $\operatorname{REE}(\mathrm{kcal} / \mathrm{d})$ & $1685 \pm 190$ & 1297 & 2074 \\
\hline RER & $0.82 \pm 0.04$ & 75 & 89 \\
\hline RFO (g/min) & $0.06 \pm 0.02$ & 0.02 & 0.09 \\
\hline RFO (mg/kg LBM/min) & $1.0 \pm 0.3$ & 0.5 & 1.6 \\
\hline \multicolumn{4}{|l|}{ Fat oxidation during exercise ${ }^{a}$} \\
\hline PFO (g/min) & $0.39 \pm 0.14$ & 0.13 & 0.81 \\
\hline PFO (mg/kg LBM/min) & $6.8 \pm 2.2$ & 2.4 & 13.7 \\
\hline $\mathrm{FAT}_{\text {MAX }}\left(\% \mathrm{VO}_{2 \text { peak }}\right)$ & $40 \pm 10$ & 26 & 72 \\
\hline \multicolumn{4}{|l|}{ Metabolic health } \\
\hline Fasting glucose (mmol/l) & $5.5 \pm 0.5$ & 4.7 & 6.6 \\
\hline Fasting insulin (IU/ml) & $3.9 \pm 3.2$ & 0.2 & 14.6 \\
\hline 2-h OGTT glucose $(\mathrm{mmol} / \mathrm{l})^{\mathrm{c}}$ & $5.1 \pm 1.1$ & 3.1 & 7.6 \\
\hline Matsuda index ${ }^{c}$ & $18.4 \pm 17.8$ & 2.3 & 64.6 \\
\hline Insulin AUC $(\mathrm{IU} / \mathrm{ml} / \mathrm{h})^{\mathrm{c}}$ & $66.1 \pm 38.4$ & 17.6 & 186.8 \\
\hline Glucose AUC $(\mathrm{mmol} / \mathrm{l} / \mathrm{h})^{\mathrm{c}}$ & $11.7 \pm 2.4$ & 8.2 & 19.4 \\
\hline
\end{tabular}

$A U C$ area under the curve, $B M I$ body mass index, $L B M$ lean body mass, $M E T$ metabolic equivalent of task, $O G T T$ oral glucose tolerance test, $P F O$ peak fat oxidation, $R E E$ resting energy expenditure, $R E R$ respiratory exchange ratio, $R F O$ resting fat oxidation, $V O_{2 p e a k}$ peak oxygen uptake

${ }^{\mathrm{a}} n=41$

$\mathrm{b}_{n=43}$

${ }^{\mathrm{c}} n=44$ participants within-pair relationships. As reported earlier (Rottensteiner et al. 2015), long-term LTPA-discordant co-twins had different body fat percentage and cardiorespiratory fitness levels. However, there were no differences in REE, RER at rest or RFO between active and inactive co-twins. On average, the active co-twins tended to have higher PFO rates and lower FAT $_{\text {MAX }}$ when compared with the inactive co-twins, but the differences were not statistically significant. In the twin individual-based analysis (Table 4), only PFO $(\mathrm{g} / \mathrm{min})$ was positively correlated with the 12-month LTMET index $(r=0.26, p=0.034)$, the Baecke score $(r=0.40, p=0.022)$ and $\mathrm{VO}_{2 \text { peak }}(1 / \mathrm{min})(r=0.51$, $p=0.028)$.

\section{Fat oxidation at rest and during exercise and metabolic health}

RFO or PFO were not correlated with fasting glucose, fasting insulin or the Matsuda index in the twin individual-based analysis (Table 4). PFO (g/min) negatively correlated with the AUC of insulin $(r=-0.42, p=0.015)$ and the AUC of glucose $(r=-0.31, p=0.050)$. In contrast, RFO positively 
Table 2 The intraclass correlation coefficients (ICCs) between MZ co-twins

\begin{tabular}{lllr}
\hline Variable & ICC & $95 \%$ CI & $p$ value \\
\hline Resting metabolism $^{\mathrm{a}}$ & & & \\
REE (kcal/day) & 0.58 & $(0.21$ to 0.80$)$ & 0.002 \\
RER & 0.51 & $(0.12$ to 0.77$)$ & 0.007 \\
RFO (g/min) & 0.54 & $(0.15$ to 0.78$)$ & 0.004 \\
RFO (mg/kg LBM/min) & 0.57 & $(0.20$ to 0.80$)$ & 0.003 \\
Fat oxidation during exercise & & & \\
PFO $(\mathrm{g} / \mathrm{min})$ & 0.67 & $(0.33$ to 0.86$)$ & $<0.001$ \\
PFO (mg/kg LBM/min) & 0.59 & $(0.21$ to 0.82$)$ & 0.002 \\
FAT $_{\text {MAX }\left(\% \text { VO }_{2 \text { peak }}\right)}$ & 0.51 & $(0.09$ to 0.77$)$ & 0.010 \\
\hline
\end{tabular}

$P F O$ peak fat oxidation, $R E E$ resting energy expenditure, $R E R$ respiratory exchange ratio, $R F O$ resting fat oxidation

${ }^{\mathrm{a}} n=21 \mathrm{MZ}$ twin pairs

$\mathrm{b}_{n}=19 \mathrm{MZ}$ twin pairs

correlated ( $r=0.31, p=0.019)$ with glucose AUC when expressed relative to LBM.

\section{Discussion}

For the first time, our study data showed that fat oxidation rates at rest and during exercise were similar between MZ co-twins, even though the study group was enriched with pairs who had discordant LTPA habits. The co-twins also exhibited similar FAT $_{\text {MAX }}$ values and thus tended to reach $\mathrm{PFO}$ at the same absolute exercise intensities. Although we were unable to confirm the effect of long-term LTPA on fat oxidation capacity in our small sub-population of long-term LTPA-discordant MZ co-twins, PFO (g/min) was associated with LTPA in the twin individual-based analysis. We also observed that PFO ( $\mathrm{g} / \mathrm{min}$ ), but not RFO, was associated with a favourable response to glucose loading.

This study's major finding is that hereditary factors influence fat oxidation capacity. The finding supports those of Toubro et al. (1998) and Bouchard et al. (1989), who reported that RER at rest and during low-intensity cycling showed significant familial resemblance. In a study involving male MZ twin pairs (Bouchard et al. 1989), the ICCs of RER ranged from 0.63 to 0.54 during cycling at low intensities $(50 \mathrm{~W}$ and $100 \mathrm{~W}$, respectively). As the researchers also investigated the substrate use of dizygotic twins, they were able to control their analysis for the common environmental effect. Their calculated heritability estimates ranged from 0.40 to 0.62 . However, as RER only describes the relative use of energy substrates, this study broadens the concept by showing that absolute fat oxidation rates behave accordingly and supports the earlier suggestion that genes play a role in determining fat oxidation capacity during exercise (Jeukendrup and Wallis 2005; Randell et al. 2016). This assumption seems evident, as the large cross-sectional studies investigating fat oxidation during exercise have been able to describe only partly the observed inter-individual variability in $\mathrm{PFO}$ (Venables et al. 2005; Randell et al. 2016; Fletcher et al. 2017).

We identified a subpopulation of MZ twin pairs, where the co-twins differed in their past 3-year LTPA. As reported earlier (Rottensteiner et al. 2015, 2016; Tarkka et al. 2016; Hautasaari et al. 2017), the LTPA discordance created diet-independent differences between active and inactive
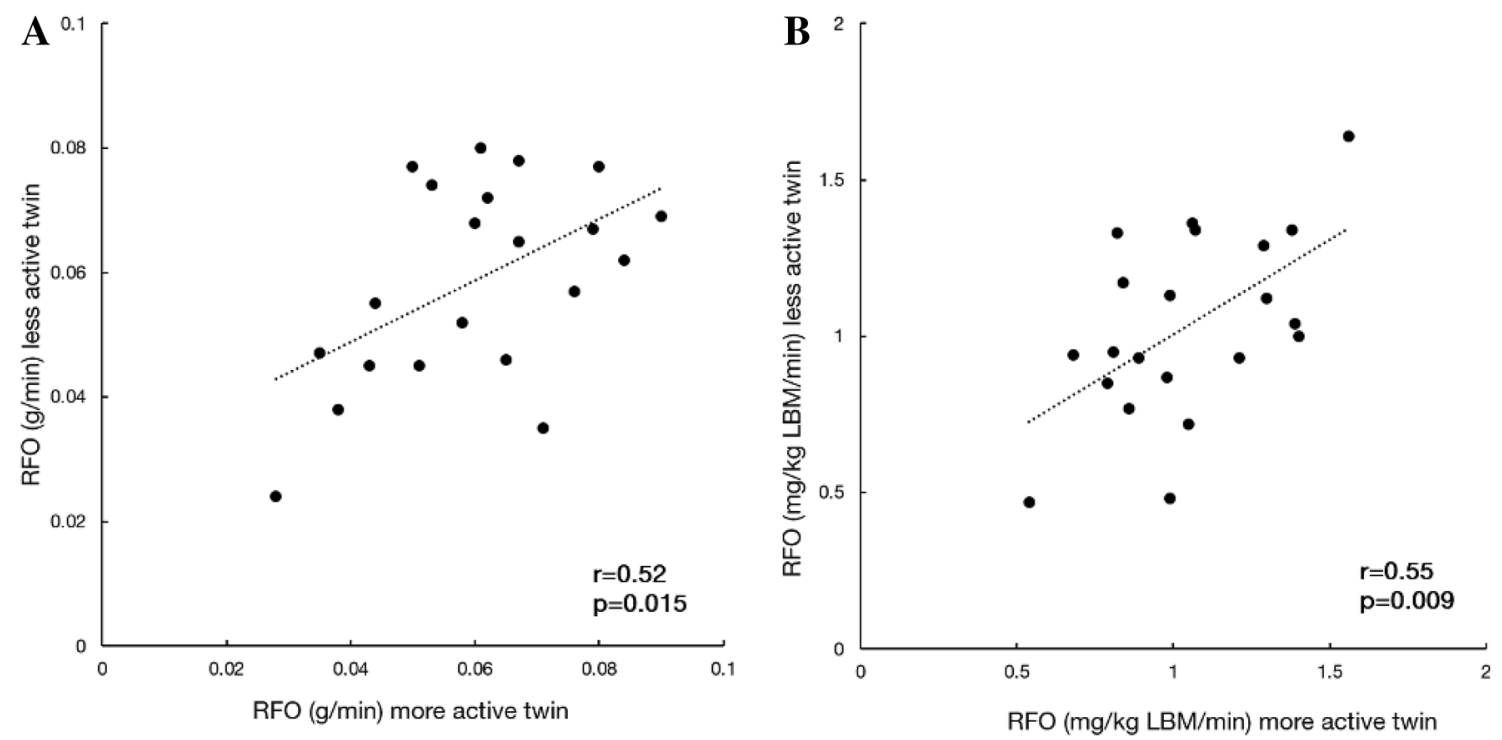

Fig. 1 Pairwise correlations of $\mathbf{a}$ absolute and $\mathbf{b}$ lean body mass (LBM) relative resting fat oxidation (RFO) in 21 MZ twin pairs 

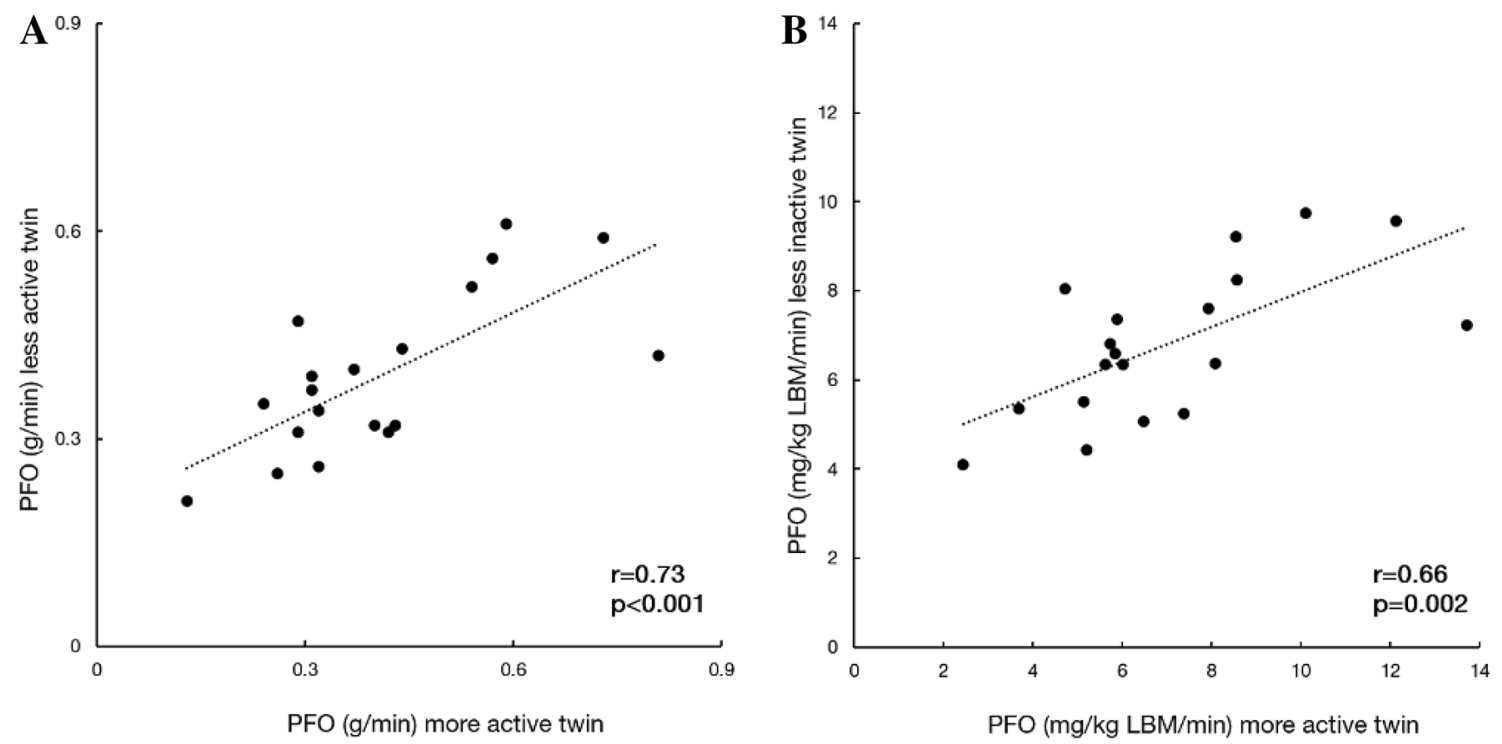

Fig. 2 Pairwise correlations of $\mathbf{a}$ absolute and $\mathbf{b}$ lean body mass (LBM) relative peak fat oxidation (PFO) during exercise in 19 MZ twin pairs

Table 3 Characteristics of the long-term-discordant MZ twin pairs

\begin{tabular}{|c|c|c|c|c|}
\hline Variable & Active $(n=10)$ & Inactive $(n=10)$ & Mean difference $(95 \% \mathrm{CI})$ & $p$ value \\
\hline \multicolumn{5}{|l|}{ Physical activity* } \\
\hline 3-year-LTMET index (MET-h/day) & $5.0 \pm 2.7$ & $1.7 \pm 1.3$ & $3.3(1.9$ to 4.8$)$ & 0.001 \\
\hline 12-month-LTMET index (MET-h/day) & $3.9 \pm 1.2$ & $1.2 \pm 0.9$ & $2.8(2.0$ to 3.5$)$ & $<0.001$ \\
\hline \multicolumn{5}{|l|}{ Body composition* } \\
\hline Lean body mass (kg) & $56.9 \pm 4.8$ & $55.5 \pm 6.1$ & $1.4(-0.3$ to 3.0$)$ & 0.094 \\
\hline Fat mass $(\mathrm{kg})$ & $16.0 \pm 4.5$ & $19.2 \pm 6.6$ & $-3.3(-6.7$ to 0.2$)$ & 0.059 \\
\hline Body fat percentage (\%) & $20.7 \pm 4.0$ & $24.0 \pm 4.6$ & $-3.3(-6.2$ to -0.4$)$ & 0.029 \\
\hline \multicolumn{5}{|l|}{ Cardiorespiratory fitness $^{\mathrm{a}}$} \\
\hline $\mathrm{VO}_{2 \text { peak }}(1 / \mathrm{min})$ & $3.3 \pm 0.3$ & $2.9 \pm 0.5$ & $0.4(0.2$ to 0.6$)$ & 0.001 \\
\hline $\mathrm{VO}_{2 \text { peak }}(\mathrm{ml} / \mathrm{kg} \mathrm{LBM} / \mathrm{min})$ & $58 \pm 5$ & $52 \pm 5$ & $7(3$ to 10$)$ & 0.001 \\
\hline \multicolumn{5}{|l|}{ Metabolism at rest ${ }^{\mathrm{b}}$} \\
\hline REE (kcal/day) & $1735 \pm 187$ & $1675 \pm 191$ & $59(-48$ to 166$)$ & 0.24 \\
\hline RER & $0.82 \pm 0.03$ & $0.80 \pm 0.03$ & $0.02(-0.01$ to 0.04$)$ & 0.16 \\
\hline RFO (g/min) & $0.06 \pm 0.02$ & $0.06 \pm 0.02$ & $0.00(-0.01$ to 0.01$)$ & 0.52 \\
\hline RFO (mg/kg LBM/min) & $1.0 \pm 0.3$ & $1.1 \pm 0.3$ & $-0.1(-0.3$ to 0.1$)$ & 0.35 \\
\hline \multicolumn{5}{|l|}{ Fat oxidation during exercise ${ }^{a}$} \\
\hline PFO (g/min) & $0.46 \pm 0.20$ & $0.38 \pm 0.12$ & $0.08(-0.02$ to 0.18$)$ & 0.11 \\
\hline PFO (mg/kg LBM/min) & $8.0 \pm 3.1$ & $6.9 \pm 1.8$ & $1.1(-0.7$ to 2.9$)$ & 0.18 \\
\hline $\operatorname{FAT}_{\text {MAX }}\left(\% \mathrm{VO}_{2 \text { peak }}\right)$ & $40 \pm 9$ & $43 \pm 8$ & $-4(-8$ to 1$)$ & 0.077 \\
\hline
\end{tabular}

$L B M$ lean body mass, $M E T$ metabolic equivalent of task, $O G T T$ oral glucose tolerance test, $P F O$ peak fat oxidation, $R E E$ resting energy expenditure, RER: respiratory exchange ratio, $R F O$ resting fat oxidation, $V O_{2 p e a k}$ peak oxygen uptake

* Data reported earlier (Rottensteiner et al. 2015)

${ }^{\mathrm{a}} n=9 \mathrm{MZ}$ twin pairs

${ }^{\mathrm{b}} n=9 \mathrm{MZ}$ twin pairs, one pair is different than in the exercise test-based variables

co-twins in cardiorespiratory fitness, intra-abdominal adiposity, glucose homeostasis, and brain morphology and function. In this study, we found no differences between the co-twins in their systemic energy metabolism at rest or during exercise. In the twin individual-based analysis, only PFO ( $\mathrm{g} / \mathrm{min}$ ) was associated with LTPA. In previous 


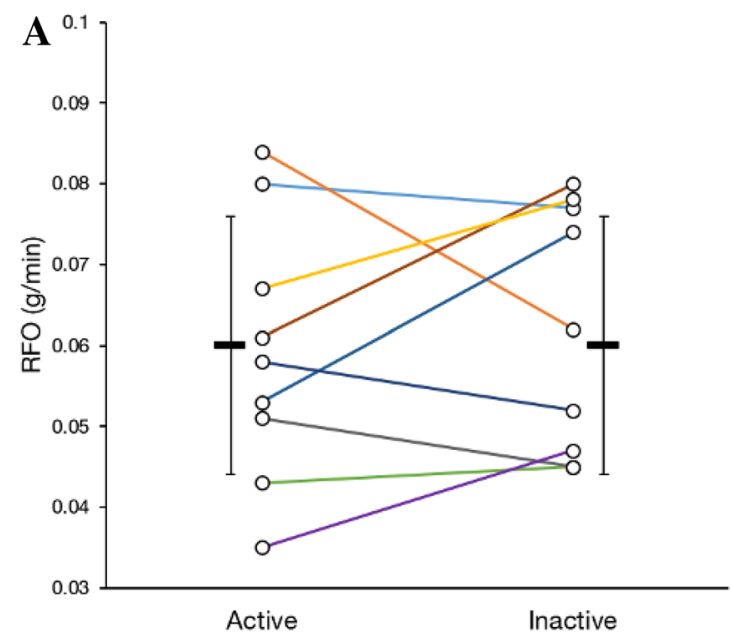

Fig. 3 a Resting fat oxidation (RFO) and b peak fat oxidation (PFO) during exercise in the leisure-time physical activity discordant $\mathrm{MZ}$ twin pairs $(n=9,8$ pairs successfully participated in both measure-

observational studies, PFO was associated with self-reported physical activity (Venables et al. 2005; Fletcher et al. 2017), and trained subjects (Nordby et al. 2006) or athletes (Dandanell et al. 2018) exhibited superior PFO compared with controls. However, it is highly likely that physical activity participation and fat oxidation capacity have shared genetic factors, and the relationship noted in observational studies is partly genetically mediated. In experimental studies, endurance-training interventions commonly increased PFO, at least in untrained populations (reviewed by Maunder et al. 2018). Earlier mechanistic evidence from our laboratory also supports the role of physical activity as a modulator of PFO. In same-sex twin pairs, an over 30-year long physical activity discordance led to significant differences in myocellular gene expression related to oxidative phosphorylation and lipid metabolism (Leskinen et al. 2010). The effects of physical activity on RFO have been investigated less, with mixed results. A modest increase in fat oxidation rates at rest has been reported in some (Barwell et al. 2009; Whyte et al. 2010) but not in all (Scharhag-Rosenberger et al. 2010) trials. When the current scientific evidence is taken together with our results, physical activity seems to be able to influence PFO, while its effect on RFO is questionable.

In the twin individual-based analysis, we observed that PFO $(\mathrm{g} / \mathrm{min})$ was associated with a favourable response to glucose loading. The observed inverse association between PFO (g/min) and insulin concentration during the OGTT was especially convincing. However, we found no association between PFO and the Matsuda index, our main surrogate of insulin sensitivity. As explained in the methods section, the Matsuda index is influenced by fasting values, which were not associated with PFO in our study. Previously, Robinson et al. (2015) showed that PFO was inversely

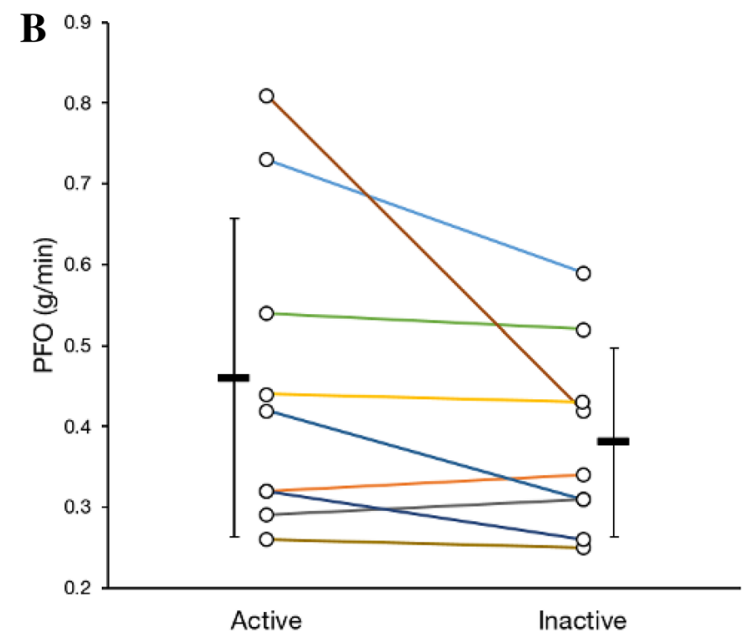

ments). Figures include group means and standard deviations. Colours represent the same twin pairs in both charts. Note the different scale in the $y$-axis

associated with a fasting-based QUICKI index. As Robinson et al. (2015) had a larger sample size $(n=53)$ and measured the PFO in the fasting state, they were more able to find the associations between the PFO and the fasting-based values, which generally vary less among healthy individuals when compared with the responses to glucose loading. Here, we show that probably an even more noticeable inverse association exists between PFO $(\mathrm{g} / \mathrm{min})$ and the insulin response to the OGTT. However, it should be mentioned that PFO does not always seem to be associated with a healthier metabolic phenotype because an obesity-related increase in fatty acid availability has also been linked to higher PFO (Ara et al. 2011; Dandanell et al. 2017a).

In contrary to PFO, RFO was not associated with a healthy metabolic response to the OGTT. Previous studies have noted mixed findings. Rosenkilde et al. (2010) reported that in a population of overweight but otherwise healthy men, the group with low RER at rest had higher PFO and a healthier metabolic profile when compared with the group with high RER. However, there were no differences in fasting glucose or insulin levels between the groups. Some case-control studies (Perseghin et al. 2002; Hodson et al. 2010) have shown an elevated RFO in obese subjects when compared with their lean counterparts. An elevated RFO could potentially function as a protective mechanism against insulin resistance (Perseghing et al. 2002) and liver fat accumulation (Hodson et al. 2010) when lipid availability increases. Overall, further research is needed to clarify the interaction between systemic fat oxidation and metabolic health.

Our study has both strengths and limitations. A key strength was our ability to measure RFO and PFO in 21 and $19 \mathrm{MZ}$ twin pairs, respectively. This enabled us to investigate 
Table 4 Results of the twin individual-based analysis

\begin{tabular}{|c|c|c|c|c|}
\hline & PFO (g/min) & PFO (mg/kg LBM/min) & $\mathrm{RFO}(\mathrm{g} / \mathrm{min})$ & $\mathrm{RFO}(\mathrm{mg} / \mathrm{kg} \mathrm{LBM} / \mathrm{min})$ \\
\hline \multicolumn{5}{|l|}{ Body composition } \\
\hline $\operatorname{BMI}\left(\mathrm{kg} / \mathrm{m}^{2}\right)$ & $\begin{array}{l}r=0.12 \\
p=0.53\end{array}$ & $\begin{array}{l}r=0.054 \\
p=0.76\end{array}$ & $\begin{array}{l}r=0.16 \\
p=0.25\end{array}$ & $\begin{array}{l}r=0.079 \\
p=0.58\end{array}$ \\
\hline Lean body mass (kg) & $\begin{array}{l}r=0.41 \\
p=0.007\end{array}$ & & $\begin{array}{l}r=0.33 \\
p=0.12\end{array}$ & \\
\hline Fat mass $(\mathrm{kg})$ & $\begin{array}{l}r=-0.13 \\
p=0.57\end{array}$ & $\begin{array}{l}r=-0.091 \\
p=0.66\end{array}$ & $\begin{array}{l}r=0.08 \\
p=0.63\end{array}$ & $\begin{array}{l}r=0.10 \\
p=0.48\end{array}$ \\
\hline \multicolumn{5}{|l|}{ Self-reported leisure time physical activity } \\
\hline 12-month LTMET-index (MET-h/day) & $\begin{array}{l}r=0.26 \\
p=0.034\end{array}$ & $\begin{array}{l}r=0.10 \\
p=0.41\end{array}$ & $\begin{array}{l}r=0.14 \\
p=0.23\end{array}$ & $\begin{array}{l}r=-0.08 \\
p=0.46\end{array}$ \\
\hline 3-year-LTMET-index (MET-h/day) & $\begin{array}{l}r=0.30 \\
p=0.081\end{array}$ & $\begin{array}{l}r=0.20 \\
p=0.26\end{array}$ & $\begin{array}{l}r=0.22 \\
p=0.13\end{array}$ & $\begin{array}{l}r=0.05 \\
p=0.32\end{array}$ \\
\hline Baecke questionnaire (score) & $\begin{array}{l}r=0.40 \\
p=0.022\end{array}$ & $\begin{array}{l}r=0.25 \\
p=0.13\end{array}$ & $\begin{aligned} r & =0.002 \\
r & =0.98\end{aligned}$ & $\begin{array}{l}r=-0.15 \\
p=0.24\end{array}$ \\
\hline \multicolumn{5}{|l|}{ Cardiorespiratory fitness } \\
\hline $\mathrm{VO}_{2 \text { peak }}(1 / \mathrm{min})$ & $\begin{array}{l}r=0.51 \\
p=0.028\end{array}$ & & $\begin{array}{l}r=0.21 \\
p=0.30\end{array}$ & \\
\hline $\mathrm{VO}_{2 \text { peak }}(\mathrm{ml} / \mathrm{kg} \mathrm{LBM} / \mathrm{min})$ & & $\begin{array}{l}r=0.36 \\
p=0.085\end{array}$ & & $\begin{array}{l}r=-0.006 \\
p=0.97\end{array}$ \\
\hline \multicolumn{5}{|l|}{ Fat oxidation during exercise } \\
\hline PFO (g/min) & & & $\begin{array}{l}r=0.30 \\
p=0.14\end{array}$ & \\
\hline PFO (mg/kg LBM/min) & & & & $\begin{array}{l}r=0.29 \\
p=0.12\end{array}$ \\
\hline \multicolumn{5}{|l|}{ Glucose homeostasis and insulin sensitivity } \\
\hline Fasting glucose (mmol/l) & $\begin{array}{l}r=-0.11 \\
p=0.42\end{array}$ & $\begin{array}{l}r=-0.16 \\
p=0.26\end{array}$ & $\begin{array}{l}r=0.084 \\
p=0.60\end{array}$ & $\begin{array}{l}r=0.05 \\
p=0.80\end{array}$ \\
\hline Fasting insulin $(\mu \mathrm{U} / \mathrm{l})$ & $\begin{array}{l}r=-0.17 \\
p=0.33\end{array}$ & $\begin{array}{l}r=-0.13 \\
p=0.48\end{array}$ & $\begin{array}{l}r=-0.10 \\
p=0.59\end{array}$ & $\begin{array}{l}r=-0.079 \\
p=0.63\end{array}$ \\
\hline Matsuda index & $\begin{array}{l}r=0.10 \\
p=0.60\end{array}$ & $\begin{array}{l}r=0.026 \\
p=0.91\end{array}$ & $\begin{array}{l}r=0.18 \\
p=0.29\end{array}$ & $\begin{array}{l}r=0.067 \\
p=0.67\end{array}$ \\
\hline Insulin AUC $(\mu \mathrm{U} / 1 / \mathrm{h})$ & $\begin{array}{l}r=-0.42 \\
p=0.015\end{array}$ & $\begin{array}{l}r=-0.35 \\
p=0.055\end{array}$ & $\begin{array}{l}r=-0.04 \\
p=0.85\end{array}$ & $\begin{array}{l}r=0.12 \\
p=0.58\end{array}$ \\
\hline Glucose AUC (mmol/l/h) & $\begin{array}{l}r=-0.31 \\
p=0.050\end{array}$ & $\begin{array}{l}r=-0.27 \\
p=0.11\end{array}$ & $\begin{array}{l}r=0.21 \\
p=0.082\end{array}$ & $\begin{array}{l}r=0.31 \\
p=0.019\end{array}$ \\
\hline
\end{tabular}

$A U C$ area under the curve, $B M I$ body mass index, $L B M$ lean body mass, $M E T$ metabolic equivalent of task, $O G T T$ oral glucose tolerance test, $P F O$ peak fat oxidation, $R E E$ resting energy expenditure, $R E R$ respiratory exchange ratio, $R F O$ resting fat oxidation, $V O_{2 p e a k}$ peak oxygen uptake

the influence of hereditary factors on RFO and PFO in a reasonably sized study group. The calculated ICCs represent the upper bound of heritability, as differences between MZ twins are due to non-genetic factors. However, as MZ twin pairs share also many aspects of their development and environment, the actual heritability of the trait may be lower. A more precise estimation of heritability would require several kinds of relatives (for quantitative trait modeling) or very large study population (for measurement of all genetic variation by whole genome sequencing). Despite our systematic nationwide search, we could only recruit $10 \mathrm{MZ}$ twin pairs, where the co-twins were long-term LTPA-discordant, which weakened our study's power to find significant pairwise differences. Furthermore, the participants' MZ twin status made it more difficult to find significant twin individualbased correlations because clustering was necessary to take into account the within-pair dependency. Additionally, since our study included only males, the results cannot be generalised to females.

Another strength of our study was our protocol's inclusion of an OGTT; we did not depend on using fastingbased values. This enabled us to conduct a more in-depth examination of the possible associations between fat oxidation and metabolic health. However, our study protocol was not optimal for PFO determination, which should be considered when interpreting the results. Nutrition intake 
the day before (Støa et al. 2016) and on the same day (Achten and Jeukendrup 2003; Edinburgh et al. 2018) will alter substrate use. In this study, we did not control for the nutrition intake before the exercise test. For example, this could partially explain why we did not find any association between RFO and PFO, as previously shown by Robinson et al. (2016). Moreover, we used 2-min exercise stages during PFO testing. The 2-min stages might be too short to reach a steady-state, especially for the subjects with lower cardiorespiratory fitness (Dandanell et al. 2017b; Chrzanowski-Smith et al. 2018). To assess whether the stage duration excessively affected the results, we compared $\mathrm{VO}_{2}$ and $\mathrm{VCO}_{2}$ between intervals $90-105 \mathrm{~s}$ and $105-120 \mathrm{~s}$ of the PFO-stage. There were no systematic differences in $\mathrm{VO}_{2}$ or $\mathrm{VCO}_{2}$ between the intervals. Mean coefficients of variation were $4 \pm 4 \%$ and $4 \pm 4 \%$ for $\mathrm{VO}_{2}$ and $\mathrm{VCO}_{2}$, respectively. Coefficient of variation of $\mathrm{VO}_{2}$, $\mathrm{VCO}_{2}$ or both exceeded $10 \%$ in 3 out of 41 participants. Removing these participants from the analyses did not materially change the results. Therefore, the influence of the stage duration was considered acceptable. Also, the measured PFO $(\mathrm{g} / \mathrm{min})$ results were associated with the most important determinants described in the literature, and as expected, correlated between the MZ co-twins. Thus, the measurements seemed to reflect the PFO of our study participants.

In conclusion, we show that fat oxidation rates at rest and during exercise are similar between MZ co-twins. Our results support the suggestion that hereditary factors influence fat oxidation capacity. The internal factors likely set the baseline for fat oxidation capacity that the external factors can modulate. In our study, the role of physical activity seemed smaller, especially concerning RFO. Furthermore, we observed that only higher capacity to utilize fatty acids during exercise associated with better metabolic health.

Acknowledgements Open access funding provided by University of Jyväskylä (JYU).

\begin{abstract}
Author contributions JEK, MR, PW and UMK conceived and designed research. MR, PW, KH and UMK conducted experiments. JK was responsible for the creation and maintenance of the base cohort from which the study sample was recruited. JEK analysed data and drafted the manuscript. All authors contributed to the interpretation of data and critical revision of the manuscript. All authors read and approved the final version of the manuscript.
\end{abstract}

Funding The FITFATTWIN study was supported by the Finnish Ministry of Education and Culture (OKM/56/626/2013 to UMK), META-PREDICT (within the European Union Seventh Framework Programme, HEALTH-F2-2012-277936 to UMK). Data collection for the FT16 study was supported by the National Institute of Alcohol Abuse and Alcoholism (grants AA-12502, AA-00145, and AA-09203 to RJ Rose) and the Academy of Finland (grants 100499, 205585, $118555,141054,264146,308248$ and 312073 to JK).

\section{Compliance with ethical standards}

Conflict of interest The authors declare that they have no conflict of interest.

Open Access This article is distributed under the terms of the Creative Commons Attribution 4.0 International License (http://creativeco mmons.org/licenses/by/4.0/), which permits unrestricted use, distribution, and reproduction in any medium, provided you give appropriate credit to the original author(s) and the source, provide a link to the Creative Commons license, and indicate if changes were made.

\section{References}

Aaltonen S, Ortega-Alonso A, Kujala UM, Kaprio J (2013) Genetic and environmental influences on longitudinal changes in leisure-time physical activity from adolescence to young adulthood. Twin Res Hum Genet. 16(2):535-543. https://doi.org/10.1017/thg.2013.9

Achten J, Jeukendrup AE (2003) The effect of pre-exercise carbohydrate feedings on the intensity that elicits maximal fat oxidation. J Sports Sci 21(12):1017-1024

Achten J, Gleeson M, Jeukendrup AE (2002) Determination of the exercise intensity that elicits maximal fat oxidation. Med Sci Sports Exerc 34(1):92-97

Ara I, Larsen S, Stallknecht B, Guerra B, Morales-Alamo D, Andersen JL, Ponce-Gonzalez JG, Guadalupe-Grau A, Galbo H, Calbet JA, Helge JW (2011) Normal mitochondrial function and increased fat oxidation capacity in leg and arm muscles in obese humans. Int J Obes 35(1):99-108. https://doi.org/10.1038/ijo.2010.123

Arden NK, Spector TD (1997) Genetic influences on muscle strength, lean body mass, and bone mineral density: a twin study. J Bone Miner Res 12(12):2076-2081

Baecke JA, Burema J, Frijters JE (1982) A short questionnaire for the measurement of habitual physical activity in epidemiological studies. Am J Clin Nutr 36(5):936-942

Barwell ND, Malkova D, Leggate M, Gill JMR (2009) Individual responsiveness to exercise-induced fat loss is associated with change in resting substrate utilization. Metabolism 58(9):13201328. https://doi.org/10.1016/j.metabol.2009.04.016

Borg GA (1982) Psychophysical bases of perceived exertion. Med Sci Sports Exerc 14(5):377-381

Bouchard C, Tremblay A, Nadeau A, Després JP, Thériault G, Boulay MR, Lortie G, Leblanc C, Fournier G (1989) Genetic effect in resting and exercise metabolic rates. 3 Metabolism 8(4):364-370

Bouchard C, Daw EW, Rice T, Pérusse L, Gagnon J, Province MA, Leon AS, Rao DC, Skinner JS, Wilmore JH (1998) Familial resemblance for VO2max in the sedentary state: the HERITAGE family study. Med Sci Sports Exerc 30(2):252-258

Chrzanowski-Smith OJ, Edinburgh RM, Betts JA, Stokes KA, Gonzalez JT (2018) Evaluation of a graded exercise test to determine peak fat oxidation in individuals with low cardiorespiratory fitness. Appl Physiol Nutr Metab 43(12):1288-1297. https://doi. org/10.1139/apnm-2018-0098

Dandanell S, Husted K, Amdisen S, Vigelsø A, Dela F, Larsen S, Helge JW (2017a) Influence of maximal fat oxidation on long-term weight loss maintenance in humans. J Appl Physiol 123(1):267274. https://doi.org/10.1152/japplphysiol.00270.2017

Dandanell S, Søndergård SD, Helge JW, Dela F, Larsen S, Præst CB, Skovborg C (2017b) Determination of the exercise intensity that elicits maximal fat oxidation in individuals with obesity. Appl Physiol Nutr Metab 42(4):405-412. https://doi.org/10.1139/ apnm-2016-0518 
Dandanell S, Meinild-Lundby AK, Andersen AB, Lang PF, Oberholzer L, Keiser S, Robach P, Larsen S, Rønnestad BR, Lundby C (2018) Determinants of maximal whole-body fat oxidation in elite crosscountry skiers: role of skeletal muscle mitochondria. Scand J Med Sci Sports 28(12):2494-2504. https://doi.org/10.1111/sms.13298

Edinburgh RM, Hengist A, Smith HA, Travers RL, Koumanov F, Betts JA, Thompson D, Walhin J, Wallis GA, Hamilton DL, Stevenson EJ, Tipton KD, Gonzalez JT (2018) Pre-exercise breakfast ingestion versus extended overnight fasting increases postprandial glucose flux after exercise in healthy men. Am J Physiol Endocrinol Metab 315(5):E1062-E1074. https://doi.org/10.1152/ajpen do.00163.2018

Flatt JP, Ravussin E, Acheson KJ, Jéquier E (1985) Effects of dietary fat on postprandial substrate oxidation and on carbohydrate and fat balances. J Clin Invest 76(3):1019-1024

Fletcher G, Eves FF, Glover EI, Robinson SL, Vernooij CA, Thompson JL, Wallis GA (2017) Dietary intake is independently associated with the maximal capacity for fat oxidation during exercise. Am J Clin Nutr 105(4):864-872. https://doi.org/10.3945/ ajcn.116.133520

Frayn KN (1983) Calculation of substrate oxidation rates in vivo from gaseous exchange. J Appl Physiol Respir Environ Exerc Physiol 55(2):628-634

Goedecke JH, St Clair Gibson A, Grobler L, Collins M, Noakes TD, Lambert EV (2000) Determinants of the variability in respiratory exchange ratio at rest and during exercise in trained athletes. Am J Physiol Endocrinol Metab 279(6):E1325-E1334

Hall LML, Moran CN, Milne GR, Wilson J, MacFarlane NG, Forouhi NG, Hariharan N, Salt IP, Sattar N, Gill JMR (2010) Fat oxidation, fitness and skeletal muscle expression of oxidative/lipid metabolism genes in South Asians: implications for insulin resistance? PLoS ONE 5(12):e14197. https://doi.org/10.1371/journ al.pone.0014197

Hautasaari P, Savić AM, Loberg O, Niskanen E, Kaprio J, Kujala UM, Tarkka IM (2017) Somatosensory brain function and gray matter regional volumes differ according to exercise history: evidence from monozygotic twins. Brain Topogr 30(1):77-86. https://doi. org/10.1007/s10548-016-0531-1

Hodson L, McQuaid SE, Humphreys SM, Milne R, Fielding BA, Frayn KN, Karpe F (2010) Greater dietary fat oxidation in obese compared with lean men: an adaptive mechanism to prevent liver fat accumulation? Am J Physiol Endocrinol Metab 299(4):E584E592. https://doi.org/10.1152/ajpendo.00272.2010

Jeukendrup AE, Wallis GA (2005) Measurement of substrate oxidation during exercise by means of gas exchange measurements. Int $\mathbf{J}$ Sports Med Suppl 1:S28-37

Lakka TA, Salonen JT (1997) The physical activity questionnaires of the Kuopio Ischemic Heart Disease Study (KIHD). A collection of physical activity questionnaires for health-related research. Med Sci Sports Exerc 29:S46-S58

Leskinen T, Waller K, Mutikainen S, Aaltonen S, Ronkainen PHA, Alén M, Sipilä S, Kovanen V, Perhonen M, Pietiläinen KH, Cheng S, Suominen H, Kainulainen H, Kaprio J, Kujala UM (2009) Effects of 32-year leisure time physical activity discordance in twin pairs on health (TWINACTIVE study): aims, design and results for physical fitness. Twin Res Hum Genet 12(1):108-117. https://doi.org/10.1375/twin.12.1.108

Leskinen T, Rinnankoski-Tuikka R, Rintala M, Seppänen-Laakso T, Pöllänen E, Alen M, Sipilä S, Kaprio J, Kovanen V, Rahkila P, Oresic M, Kainulainen H, Kujala UM (2010) Differences in muscle and adipose tissue gene expression and cardio-metabolic risk factors in the members of physical activity discordant twin pairs. PLoS 5:e12609. https://doi.org/10.1371/journal.pone.0012609

Mansell PI, Macdonald IA (1990) Reappraisal of the Weir equation for calculation of metabolic rate. Am J Physiol 258(6):1347-1354
Matsuda M, DeFrozo RA (1991) Insulin sensitivity indices obtained from oral glucose tolerance testing. Comparison with the euglycemic insulin clamp. Diabetes Care 22(9):1462-1470

Maunder E, Plews DJ, Kilding AE (2018) Contextualising Maximal Fat Oxidation During Exercise: Determinants and Normative Values. Front Physiol. https://doi.org/10.3389/fphys.2018.00599

Mustelin L, Joutsi J, Latvala A, Pietiläinen KH, Rissanen A, Kaprio J (2012) Genetic influences on physical activity in young adults: a twin study. Med Sci Sports Exerc 44(7):1293-1301. https://doi. org/10.1249/MSS.0b013e3182479747

Nordby P, Saltin B, Helge JW (2006) Whole-body fat oxidation determined by graded exercise and indirect calorimetry: a role for muscle oxidative capacity? Scand J Med Sci Sports 16(3):209-214

Perseghin G, Scifo P, Danna M, Battezzati A, Benedini S, Meneghini E, Del Maschio A, Luzi L (2002) Normal insulin sensitivity and IMCL content in overweight humans are associated with higher fasting lipid oxidation. Am J Physiol Endocrinol Metab 283(3):556-564

Phielix E, Meex R, Ouwens DM, Sparks L, Hoeks J, Schaart G, Moonen-Kornips E, Hesselink MK, Schrauwen P (2012) High oxidative capacity due to chronic exercise training attenuates lipid-induced insulin resistance. Diabetes 61(10):2472-2478

Randell R, Rollo I, Roberts T, Dalrymple K, Jeukendrup A, Carter $\mathrm{J}$ (2016) Maximal fat oxidation rates in an athletic population. Med Sci Sports Exerc 49(1):133-140. https://doi.org/10.1249/ MSS.0000000000001084

Robinson SL, Hattersley J, Frost GS, Chambers ES, Wallis GA (2015) Maximal fat oxidation during exercise is positively associated with 24-hour fat oxidation and insulin sensitivity in young, healthy men. J Appl Physiol 118(11):1415-1422. https://doi.org/10.1152/ japplphysiol.00058.2015

Robinson SL, Chambers ES, Fletcher G, Wallis GA (2016) Lipolytic markers, insulin and resting fat oxidation are associated with maximal fat oxidation. Int J Sports Med 37(8):607-613. https:// doi.org/10.1055/s-0042-100291

Romijn JA, Coyle EF, Sidossis LS, Gastaldelli A, Horowitz JF, Endert E, Wolfe RR (1993) Regulation of endogenous fat and carbohydrate metabolism in relation to exercise intensity and duration. Am J Physiol 265(3 Pt 1):E380-E391

Rosenkilde M, Nordby P, Nielsen LB, Stallknecht BM, Helge JW (2010) Fat oxidation at rest predicts peak fat oxidation during exercise and metabolic phenotype in overweight men. Int J Obes 34(5):871-877. https://doi.org/10.1038/ijo.2010.11

Rottensteiner M, Leskinen T, Niskanen E, Aaltonen S, Mutikainen S, Wikgren J, Heikkilä K, Kovanen V, Kainulainen H, Kaprio J, Tarkka I, Kujala U (2015) Physical activity, fitness, glucose homeostasis, and brain morphology in twins. Med Sci Sports Exerc 47(3):509-518. https://doi.org/10.1249/MSS.0000000000000437

Rottensteiner M, Leskinen T, Järvelä-Reijonen E, Väisänen K, Aaltonen S, Kaprio J, Kujala UM (2016) Leisure-time physical activity and intra-abdominal fat in young adulthood: a monozygotic co-twin control study. Obesity 24(5):1185-1191. https://doi. org/10.1002/oby. 21465

Scharhag-Rosenberger F, Meyer T, Walitzek S, Kindermann W (2010) Effects of one year aerobic endurance training on resting metabolic rate and exercise fat oxidation in previously untrained men and women. Metabolic endurance training adaptations. Int J Sports Med. 31(7):498. https://doi.org/10.1055/s-0030-1249621

Simoneau JA, Bouchard C (1995) Genetic determinism of fiber type proportion in human skeletal muscle. FASEB J 9(11):1091-1095

Støa EM, Nyhus L, Børresen SC, Nygaard C, Hovet ÅM, BratlandSanda S, Helgerud J, Støren Ø (2016) Day to day variability in fat oxidation and the effect after only 1 day of change in diet composition. Appl Physiol Nutr Metab 41(4):397-404. https:// doi.org/10.1139/apnm-2015-0334 
Stubbe JH, Boomsma DI, Vink JM, Cornes BK, Martin NG, Skytthe A, Kyvik KO, Rose RJ, Kujala UM, Kaprio J, Harris JR, Pedersen NL, Hunkin J, Spector TD, de Geus EJ (2006) 2006 Genetic influences on exercise participation in 37,051 twin pairs from seven countries. PLoS ONE 1:e22. https://doi.org/10.1371/journ al.pone. 0000022

Tarkka IM, Savić A, Pekkola E, Rottensteiner M, Leskinen T, Kaprio J, Kujala UM (2016) Long-term physical activity modulates brain processing of somatosensory stimuli: evidence from young male twins. Biol Psychol 117:1-7. https://doi.org/10.1016/j.biops ycho.2016.02.001

Toubro S, Sørensen TI, Hindsberger C, Christensen NJ, Astrup A (1998) Twenty-four-hour respiratory quotient: the role of diet and familial resemblance. J Clin Endocrinol Metabs 83(8):2758-2764

Venables MC, Achten J, Jeukendrup AE (2005) Determinants of fat oxidation during exercise in healthy men and women: a crosssectional study. J Appl Physiol 98(1):160-167. https://doi. org/10.1152/japplphysiol.00662.2003
Waller K, Kaprio J, Kujala UM (2008) Associations between long-term physical activity, waist circumference and weight gain: a 30-year longitudinal twin study. Int J Obes 32(2):353-361. https://doi. org/10.1038/sj.ijo.0803692

Weir JB (1949) New methods for calculating metabolic rate with special reference to protein metabolism. J Physiol 109(1-2):1-9

Whyte LJ, Gill JMR, Cathcart AJ (2010) Effect of 2 weeks of sprint interval training on health-related outcomes in sedentary overweight/obese men. Metab Clin Exp 59(10):1421-1428. https:// doi.org/10.1016/j.metabol.2010.01.002

Williams RL (2000) A note on robust variance estimation for clustercorrelated data. Biometrics 56(2):645-646

Publisher's Note Springer Nature remains neutral with regard to jurisdictional claims in published maps and institutional affiliations. 